\title{
Pentecostalismo brasileiro em Moçambique: produção de conhecimento espiritual e cultural em um espaço transnacional
}

Linda van de Kamp*

Resumo: Alinhado com uma história da religião e da cura no sudeste da África, o pentecostalismo brasileiro em Moçambique criou condições para uma mobilidade em termos culturais e espirituais. Argumenta-se, assim, que o pentecostalismo transnacional estimula as mulheres, com uma mobilidade socioeconômica ascendente, a desenvolverem sua posição crítica em relação às culturas locais. Mulheres moçambicanas que participam das igrejas pentecostais brasileiras tornam-se transnacionais, embarcam em uma viagem em que se confrontam com percepções, valores e práticas socioculturais, pois atravessam subjetivamente as fronteiras nacionais, na medida em que criticam e se distanciam de certas formas de conhecimentos culturais e espirituais locais. Assim, o pentecostalismo brasileiro, em Moçambique, contribui para uma consciência cultural crítica das mulheres e para uma desestabilização da continuidade cultural, tornando-se pessoas "estrangeiras" dentro de sua própria sociedade. Nesse sentido, mulheres pentecostais não necessariamente respondem a situações de mobilidade, tal como ocorre nos processos de globalização, mas, ao contrário, criam mobilidades socioculturais através do poder do Espírito Santo para conquistar novos modos de ser e fazer, em particular nas áreas de gênero, parentesco e casamento.

Palavras-chave: pentecostalismo brasileiro, transnacionalismo Sul-Sul, mobilidade cultural e espiritual, Moçambique.

\section{Introdução}

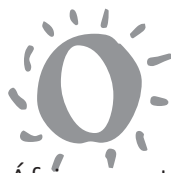

pentecostalismo brasileiro é um fenômeno relativamente novo na África Austral e ganhou maior proeminência em Moçambique, Angola e na África do Sul (Freston, 2005; Oro et alii, 2003). As igrejas brasileiras em África pertencem ao novo ramo do cristianismo global neopentecostal, que está crescendo na África, América Latina e Ásia. As mesmas salientam a importância de uma experiência pessoal direta com Deus através da incorporação do Espírito Santo por seguidores de Jesus Cristo (Anderson, 2004; Asamoah-Gyaduh, 2013; Freston, 2001). Dão especial relevo aos dons do Espírito Santo, como seja a capacidade de falar em línguas diversas (glossolalia), profecia, sonhos e visões, cura, oração e libertação de espíritos malignos. A visão neopentecostal do mundo - o local de uma batalha espiritual entre forças demoníacas e celestiais - justifica uma missão global pentecostal para difundir o Evangelho em todas as nações. A maior parte das igrejas pentecostais opera em redes globais de intercâmbio, para as quais são fundamen-

\author{
* Antropóloga e \\ professora adjunta \\ no Departamento \\ de Sociologia da \\ Universidade de \\ Amsterdam, Holan- \\ da. <l.j.vandekamp@ \\ uva.nl>.
}


tais os meios públicos de comunicação, bem como a circulação de líderes carismáticos, discursos pentecostais, livros, filmes e todos os demais meios de divulgação para chegar a localidades do mundo inteiro, no âmbito do projeto da fé para transformar nações, comunidades e vidas pessoais através do poder do Espírito Santo (Coleman, 2000; Gifford, 2004; Meyer, 2010).

A maior parte dos missionários evangélicos brasileiros na África instalaram-se em Moçambique (Freston, 2005: 55). Hoje, as igrejas brasileiras estão integradas às paisagens periurbanas do país e se tornaram cada vez mais influentes nos últimos anos, principalmente na capital Maputo (Kamp, 2011). A mais influente instituição religiosa brasileira é a Igreja Universal do Reino de Deus - Igreja Universal -, apesar das críticas que recebe em decorrência de sua abordagem agressiva diante da "cultura africana" e por sua centralidade nos dízimos e grandes oferendas financeiras.

Atualmente, a Igreja Mundial do Poder de Deus, que é dirigida por um bispo egresso da Igreja Universal, está se expandindo rapidamente. Outra igreja proeminente, embora menor, é a Pentecostal Deus é Amor - esta foi uma das que iniciaram a era neopentecostal no Brasil (Chesnut, 1997). Nos últimos anos, estabeleceram-se outras conhecidas igrejas neopentecostais brasileiras em Moçambique, como a Igreja Internacional da Graça de Deus, além de um bom número de missionários brasileiros que passaram a edificar suas próprias igrejas independentes. Também há missionários brasileiros trabalhando nas igrejas pentecostais clássicas, como a Assembleia de Deus, reconhecida como a maior igreja pentecostal (e talvez até mesmo protestante e evangélica) em Moçambique. Foi fundada no início do século XX (Upton, 1980). Moçambique recebeu também a Igreja Baptista Renovada, que tem algumas caraterísticas neopentecostais. Várias instituições neopentecostais - criadas pelos próprios moçambicanos - mantêm laços estreitos com o Brasil, como a Igreja Evangelho em Acção, que está em rápida expansão. Essas igrejas partilham a visão sobre o mundo como o local de uma batalha espiritual entre forças malignas e celestiais em que muitas "tradições africanas" são percebidas como demoníacas.

1. Quando me refiro a igrejas pentecostais ou a pentecostalismo, neste artigo, reporto-me às igrejas neopentecostais e do neopentecostalismo.
O pentecostalismo brasileiro ${ }^{1}$ em Moçambique floresce particularmente entre as mulheres das zonas urbanas. Quase 75\% dos visitantes e convertidos das igrejas pentecostais brasileiras em Maputo são mulheres de várias idades com uma mobilidade socioeconômica ascendente. Elas geralmente ganham alguma renda e muitas apresentam um nível de formação escolar relativamente elevado. A introdução de uma economia de mercado neoliberal, como resultado dos programas de ajustamento estrutural do final da década de 1980, a implementação de estruturas políticas e sociais mais democráticas e a afluência e ascensão de organizações não 
governamentais centradas nos direitos e emancipação das mulheres estimularam o acesso das mulheres à educação e a novas carreiras profissionais (Andrade et alii, 2001: 134-138; Casimiro, 2004: 146; Sheldon, 2002: 229-266). A posição socioeconômica ascendente dessas mulheres colocou-as em novas áreas socioculturais. Em contraste com as gerações anteriores de mulheres das cidades, cada vez mais mulheres urbanas não dependem mais do casamento para garantir sua sobrevivência econômica (ver Penvenne, 1997). Seu papel na reprodução biológica também já não é decisivo para definir sua posição e identidade. Essas mulheres estão explorando novos estilos de vida e diferentes posições culturais, vivendo por conta própria, escolhendo seu parceiro sem a interferência da família ou optando por ficarem solteiras e construindo suas próprias casas. Além de novas oportunidades, as novas circunstâncias estão levantando dúvidas, conflitos e incertezas. Por exemplo: apesar de sua crescente independência socioeconômica - ou justamente por causa dela -, muitas mulheres jovens não conseguem encontrar um parceiro "bom" e "fiel". Os homens têm medo que as mulheres ganhem ou possam ganhar mais do que eles e que percam, consequentemente, sua influência sobre as próprias mulheres (ver Manuel, 2011). Do mesmo modo, os sogros não têm a certeza de que essas mulheres serão boas donas de casa. Em poucas palavras, essas mulheres estão aproveitando as novas possibilidades econômicas e socioculturais que surgem, mas, como os seus parceiros e sogros, elas também estão inseguras sobre como cumprir este seu novo papel. Elas não têm outras pessoas em suas famílias que sirvam de modelo, pois muitas vezes constituem a primeira geração que frequenta o ensino superior e funda uma empresa (Kamp, 2012a). Integram importante segmento dos seguidores das igrejas pentecostais brasileiras. Durante os cultos em suas igrejas, os pastores brasileiros abordam os novos desafios que essas mulheres estão enfrentando.

Neste artigo, focalizo algumas dimensões transnacionais do pentecostalismo brasileiro em Moçambique. Analiso, em especial, como as mulheres que têm experimentado uma mobilidade socioeconômica ascendente, exploram as formas de mobilidade que o pentecostalismo transnacional gera e difunde. Muitos estudos têm mostrado como formas religiosas têm viajado com migrantes e criaram grupos religiosos em seus novos países, formando movimentos religiosos transnacionais. No entanto, no caso de Moçambique, as igrejas brasileiras não se dirigem a uma comunidade de migrantes brasileiros, mas aos próprios moçambicanos. Através do pentecostalismo brasileiro e envolvendo-se nas ideias e práticas de pastores brasileiros, moçambicanos podem tornar-se transnacionais, como procuro demonstrar ao longo deste artigo. Pastores pentecostais proclamam que a fé é capaz de mover vidas, famílias e nações (Dijk, 2006) e que as pessoas não precisam aceitar um salário baixo, morar em uma pequena casa e viver um casamento infeliz. Essas situações representam inércia e estagnação e mostram que algo está 
bloqueando o seu bem-estar e sua prosperidade. O poder do Espírito Santo, de acordo com a pregação e o entendimento neopentecostal do Evangelho, remove bloqueios e produz sucessos enormes. Nações inteiras podem avançar e progredir com a força da fé pentecostal. A centralidade dessa mensagem esteve sempre presente nos cultos que testemunhei. É justamente durante estes cultos, para os fiéis, que o poder do Espírito Santo se manifesta: nas danças, na música pulsante e em corpos trêmulos. Além disso, as fronteiras são constantemente cruzadas por pastores que viajam por todo o mundo em seus esforços para abrir novas igrejas em localidades diferentes.

Na primeira parte do artigo, apresento uma visão geral sobre as dimensões históricas da relação entre religião e mobilidade no sudeste da África, mantendo o foco no caso moçambicano. Mostro que o poder de curandeiros depende, muitas vezes, de sua capacidade de transcender limites. Por exemplo: a chegada de missionários cristãos, no passado, permitiu às pessoas de se apropriarem de práticas poderosas, ideias e técnicas exógenas que foram cruciais para progredir em termos políticos, espirituais, culturais e socioeconômicos.

Na segunda parte, dedico-me à análise da mobilidade proporcionada pelo pentecostalismo brasileiro transnacional em Moçambique e sua relação com a situação cultural local, destacando como o espaço transnacional Sul-Sul (Brasil-Moçambique) desafia convertidos para refletir criticamente sobre suas culturas nacionais. Darei exemplos de mulheres moçambicanas que consideram o pentecostalismo transnacional atraente porque, de seu ponto de vista, aspectos de imobilidade na cultura moçambicana contrastam com as oportunidades de mobilidade sociocultural e espiritual que o espaço pentecostal brasileiro oferece mediante os comportamentos pentecostais na tomada de decisões, nas iniciativas, possibilitando ainda certa independência nas relações de parentesco.

2. A pesquisa etnográfica em Moçambique teve lugar entre agosto de 2005 e agosto de 2007 , como parte da pesquisa do doutorado patrocinado pela Organização Holandesa para Pesquisa Científica (NWO), e nos meses de julho e agosto de 2008 e 2011.
Metodologicamente, este trabalho baseia-se no estudo da literatura sobre religião e missão no sudeste da África e em pesquisa etnográfica realizada principalmente na cidade de Maputo, durante um período de 26 meses, entre 2005 e $2011^{2}$. A pesquisa centrou-se no processo de conversão ao pentecostalismo brasileiro de moçambicanos urbanos, que creditam sua atitude à política cultural pentecostal - especialmente no que diz respeito à família, ao casamento, à sexualidade. A análise concentra-se na ligação transnacional Sul-Sul do pentecostalismo brasileiro em Moçambique, a partir da perspectiva de moçambicanos pentecostais. Embora tenha entrevistado vários pastores brasileiros, as igrejas e a sua organização não eram o enfoque principal do trabalho de campo, mas sim os próprios convertidos. 
A centralidade do pentecostalismo está ligada a uma tradição de práticas de cura e missões no sudeste da África, incluindo países como Moçambique, Malawi, Botswana, Zimbabwe, Tanzânia e África do Sul. O que é fundamental para o perfil dos profetas, missionários e curandeiros, nesta região, é o ato de cruzar fronteiras (Luedke \& West, 2006³; Rekdal, 1999; Whyte, 1988)4. Por exemplo: todos os curandeiros em Maputo parecem vir de outro lugar, seja de outras partes de Moçambique, seja de outro país da região (Luedke \& West, 2006: 1). Curandeiros moçambicanos, em suas propagandas, salientam suas experiências em outros países. Fazer uso de conhecimento "estrangeiro" parece comprovar a eficácia de suas técnicas de cura e de seus medicamentos. Curandeiros, pastores e profetas populares parecem vir do outro lado de alguma fronteira. Fronteiras e limites não são apenas nacionais e geográficos, mas também culturais, linguísticos, científicos e religiosos. Os curandeiros são, frequentemente, seres ambivalentes. Enquanto os outros devem comportar-se como todo mundo, os curandeiros podem cruzar fronteiras, socialmente aceitas, o que lhes daria o poder de curar (Bagnol, 2006). Eles detêm poderes espirituais que Ihes permitem cruzar fronteiras temerárias, fronteiras demasiadamente perigosas para os outros atravessarem ${ }^{5}$. Vários rituais de cura, como rituais de limpeza depois da última guerra em Moçambique (Granjo, 2007), incluem a travessia de fronteiras, movendo-se de uma posição poluída para uma posição pura.

Séculos de interação entre as pessoas na África Austral - como resultado do comércio, das guerras e do trabalho migratório - têm contribuído para a aprendizagem de outras técnicas de cura (Feierman, 2006) ${ }^{6}$. Ademais, a chegada de missionários e médicos europeus acrescentou a importância da transgressão de limites para o poder de cura. Mesmo nos primeiros encontros entre africanos e europeus, ambas as partes absorveram aspectos das práticas e técnicas de cura de cada um, as quais foram experimentadas como poderosas e eficazes (Comaroff \& Comaroff, 1997: 364; Vaughan apud Luedke \& West, 2006: 4). Curandeiros africanos incorporaram elementos cristãos, muçulmanos e científicos em suas práticas, como o Alcorão, a Bíblia, luvas médicas e vestidos brancos ${ }^{7}$. A chegada de missões cristãs em Moçambique permitiu às pessoas de se apropriarem de práticas, ideias e técnicas poderosas que foram cruciais para progredir política, cultural e socioeconomicamente (Cruz \& Silva, 2001a; Macamo, 1998; 2005; West, 2005: 109-132). Isso será apresentado na sequência do artigo, a partir de uma perspectiva de gênero para o caso do sul de Moçambique, mais especificamente da capital Maputo.
3. Luedke \& West (2006) também mostram como os curandeiros reproduzem e criam fronteiras.

4. Ver Werbner (1989) para observações semelhantes em outras partes da África e do mundo.

5. As perspectivas sobre cura e o cruzamento de fronteiras relacionamse à tradição antropológica de estudar liminaridade. Ver Turner (1967) e Gennep (1980).

6. Cultos territoriais e regionais são um exemplo dessa troca (Schoffeleers, 1979; Werbner, 1977).

7. Para o Moçambique, ver Luedke (2007) e West (2005: 120126). 
8. Embora poucas crianças tivessem a oportunidade de frequentar uma escola. No fim da época colonial, apenas $5,7 \%$ das crianças com idade escolar estavam matriculados (Sheldon, 2002: 80).

\section{Para o caso} específico do Moçambique, ver Casimiro (1986: 4445) e Sheldon (2002: 79-113).

10. Originalmente, as igrejas africanas independentes foram formadas como dissidências de igrejas missionárias ou foram fundadas por africanos para africanos.

11. Palestra do pastor Américo Zavala na igreja Presbiteriana de Magude, em 18 de julho de 2008.

\section{Igrejas missionárias e igrejas africanas independentes} formando o Estado-nação moçambicano

As igrejas protestantes e católicas tinham uma função importante no âmbito da educação e no acesso à economia durante o período colonial em Moçambique. Em geral, as autoridades coloniais colaboravam com a Igreja Católica, enquanto os protestantes mantinham uma relação difícil com as autoridades (Cruz e Silva, 2001a; Helgesson, 1994). Por meio de seus programas de educação, as missões católicas desempenhavam um papel importante no projeto colonial de unificação nacional e de formação do Estado-nação projetado pelas autoridades portuguesas (Sheldon, 2002: 79-113) ${ }^{8}$. Enquanto a missão católica incorporava principalmente os homens nestes programas, Sheldon (2002: 28) observa que algumas mulheres se mudavam para os centros de missão católicos no intuito de escapar dos casamentos infelizes. Para algumas moçambicanas, as estações missionárias eram uma alternativa para a vida familiar local, o que reforçava a visão negativa que os missionários tinham sobre a vida familiar africana (Sheldon 2002: 87). A educação servia para transformar as mulheres africanas em donas de casa à maneira europeia, ensinando-lhes habilidades domésticas que eram vistas como desejáveis para entrar na economia colonial (Comaroff \& Comaroff, 1997) ${ }^{9}$. Com isso, uma pequena classe de mulheres católicas educadas também podia identificar-se com o projeto do Estado-nação.

Um projeto de Estado-nação alternativo desenvolveu-se nas missões protestantes. Em relação aos protestantes, pesava a suspeita de trabalharem contra os interesses das autoridades portuguesas e de estimularem uma identidade nacional indígena que se opunha à dominação colonial (Cruz e Silva, 2001a). A maior parte das igrejas missionárias protestantes e igrejas independentes africanas ${ }^{10}$, no sul de Moçambique, foram iniciadas por migrantes retornados (Harries, 2007; Helgesson, 1994: 131-136), particularmente mineiros moçambicanos regressados da África do Sul, onde haviam entrado em contato com missões e igrejas independentes africanas nas minas. O conhecimento que tinham adquirido sobre o cristianismo e sua capacidade de ler a Bíblia eram vantagens positivas na volta para a casa. Um pastor da Igreja Presbiteriana, ligada à Missão Protestante Suíça na África do Sul, afirma a esse respeito: "Imagine! Uma pessoa negra, durante o período colonial, sendo capaz de ler!"11.

O caso da influente Missão Suíça, hoje Igreja Presbiteriana, é o mais ilustrativo desta condição. Tudo começou com um evangelista moçambicano, Yosefa Mhalamhala, que veio das minas na África do Sul (Butselaar, 1987: 49-65; Harries, 2007: 77-82). Como a igreja emergente operou fora do controle do governo português, não era possível estabelecer uma missão na cidade de Lourenço Marques - que, com a Independência, tornou-se Maputo - e estabeleceu-se e cresceu na região de Gaza, onde 
havia um maior controle exercido por reinóis locais. No início da década de 1980, a Missão Suíça foi especialmente popular entre as mulheres na região de Gaza. Elas se convertiam depois de experimentarem poderosas visões e sonhos (Harries, 2007: 84-85). Viram o surgimento de novas oportunidade, até então impensáveis, graças à religião, ainda sob a perspectiva das pequenas possibilidades que conheciam sob as autoridades coloniais, em comparação aos homens, que podiam, por exemplo, ir a novos lugares como trabalhadores migrantes. Como as mulheres eram tradicionalmente especialistas espirituais, o seu envolvimento na nova religião era uma extensão de suas próprias práticas. Alguns líderes da Missão Suíça estavam preocupados com a influência de mulheres com "tendências emocionais", muito semelhantes às práticas locais de se estabelecer contatos com os antepassados através dos sonhos e das visões. Eles temiam que os convertidos entendessem de modo equivocado o verdadeiro espírito do cristianismo.

Durante a primeira metade do século XX, era mais fácil operar em Lourenço Marques, onde a Missão Suíça atraiu muitos novos seguidores, enquanto o número de adeptos nas áreas rurais estagnou (Harries, 2007: 101). Na cidade, a igreja desempenhou um papel fundamental entre a população indígena jovem e urbana, cujas famílias, em sua maioria, integravam a economia colonial. Esses jovens foram crescendo no período do Estado Novo português, a partir de 1926, quando o Indigenato estava sendo introduzido. O sistema do Indigenato foi implementado pelos colonizadores, e consistia na simples distinção entre cidadãos (brancos colonos) e indígenas (nativos, naturais da terra). Legalmente, não sendo cidadão, o moçambicano não possuía direitos civis, sendo obrigado a laborar em profissões menores ou ainda banido ao trabalho forçado, sempre relegado a escolas inferiores (Meneses, 2010: 82)12. A Missão Suíça passou a oferecer à população nativa uma educação nas línguas vernaculares, em oposição à educação em língua portuguesa, oferecida pelos católicos. De acordo com Cruz e Silva (2001a), essa educação e os debates organizados no âmbito da Igreja Protestante contribuíram para a formação de uma consciência política e o seu desdobramento em sentimentos nacionalistas baseados em lealdades locais, ao invés de lealdade para com o português.

Enquanto a maior parte dos correligionários era masculina, as mulheres também faziam parte das missões protestantes em Lourenço Marques. Algumas tinham papéis influentes, a exemplo da escritora Lina Magaia (Cruz e Silva, 2001a). Mesmo se meninas e meninos tivessem a oportunidade de participar no sistema de educação de jovens da igreja, para as meninas a educação era orientada para a vida familiar, para o lar e à cozinha (Cruz e Silva, 2001a: 53-54). Várias lideranças da Frente da Libertação de Moçambique (Frelimo), o maior e mais influente partido político até hoje formado no país, foram educados pelas missões protestantes, entre eles, seu fundador, Eduardo Mondlane (Missão Suíça), Samora Machel (Metodista), o

\footnotetext{
12. Alguns

"indígenas" podiam tornarse "assimilados", designação para os antigos "indígenas" que haviam adquirido a cidadania portuguesa após provarem sua capacitação em uma série de quesitos, como, por exemplo, falar corretamente a língua portuguesa e ter bom comportamento (Meneses, 2010: 85).
} 
13. Sobre as ambiguidades nas relações entres os protestantes e a Frelimo, ver MorierGénoud (1996) e Rossouw e Macamo (1993).

\section{Por exemplo:} os membros da Igreja Assembleia de Deus contaram-me sobre o episódio do encarceramento de seu pastor Mulungu (Morier-Génoud, 1996, p. 29). Mas outros disseram-me que nunca houve qualquer perseguição de crentes. As experiências variam (Morier-Génoud, 1996; Koevering, 1992: 107). A Constituição diz que os cidadãos tinham a liberdade de crer ou não crer em uma religião, mas os seus direitos não estavam claros e eram imprecisos (MorierGénoud, 1996: 27).

15. Termo empregado por um convertido pentecostal, 42 anos de idade, cuja família integrava a comunidade católica no bairro Chamanculo. Ele disse-me que, durante a presidência de Machel, a religião tinha sido proibida, e "não nos importamos mais com a Igreja Católica" e que a moralidade desapareceu com a subsequente guerra civil (conversa em 21 de fevereiro de 2005). primeiro presidente de Moçambique depois da Independência, e Armando Emílio Guebuza (Missão Suíça), presidente de Moçambique de 2005 até 2014. Após a Independência, muitos líderes políticos vieram dessas igrejas protestantes e é neste sentido que as igrejas protestantes se tornaram intimamente ligadas à formação do Estado-nação, assim como a Igreja Católica estava vinculada ao projeto do Estado colonial português.

Logo após a Independência, o governo marxista-leninista da Frelimo adotou uma postura antirreligiosa. A Igreja Católica, em razão de sua colaboração com o regime colonial (Morier-Génoud, 1996), e as Testemunhas de Jeová (Carvalho, 2005: 21-22; Morier-Génoud, 1996: 29), que abertamente resistiram às políticas nacionalistas da Frelimo, sofreram com o posicionamento do partido revolucionário acerca da religião. Os curandeiros tradicionais também foram perseguidos (Lundin, 2007: 107108; Pinsky, 1982: 41). As igrejas protestantes, de onde vieram a maioria dos líderes da Frelimo, estavam mais perto do Estado, mas também sofreram com a política antirreligiosa (Cruz e Silva, 2008: 164) ${ }^{13}$. Pastores dessas igrejas foram presos e tornou-

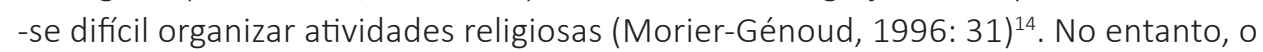
colapso da economia e a crescente dependência da Frelimo em relação à sociedade civil para a distribuição de alimentos, roupas e de instalação de equipamentos escolares e médicos, especialmente no período da guerra entre Frelimo e a Resistência Nacional Moçambicana (Renamo), em torno dos anos 1976-1992, mudaram a política de relacionamento entre o Estado e as igrejas. Além disso, as políticas da Frelimo frente à religião estavam gerando publicidade negativa, contrastando com a imagem geralmente positiva da Renamo a esse respeito, que era a favor da religião e recebeu apoio de grupos da sociedade civil do Ocidente, principalmente dos Estados Unidos (Koevering, 1992: 109, 115-116, 123-124; Morier-Génoud, 1996: 57). No início dos anos 1980, estabeleceu-se um novo período de diálogo mais construtivo entre a Frelimo e as igrejas (Morier-Génoud, 1996: 57-58; Koevering, 1992: 107). O presidente Samora Machel confirmou que juntos - o governo e as igrejas - iriam melhorar a situação dos moçambicanos, mas um clima mais liberal só foi efetivamente iniciado em 1986, com o sucessor de Machel, o presidente Joaquim Chissano (Seibert, 2005: 132-133). A plena liberdade religiosa foi introduzida com a Constituição democrática de 1990. Católicos e protestantes intervieram então com sucesso nas negociações de paz entre o governo da Frelimo e os líderes da Renamo, que assinaram um acordo de paz, o Acordo de Roma, em 1992, após 16 anos de luta dentro do território nacional (Vines \& Wilson, 1995).

A posição antirreligiosa da Frelimo deixou sua marca em Maputo. Vários dos meus interlocutores mais velhos contaram como a importância da vida religiosa tinha diminuído (veja, também, Pinsky 1982: 41). Além disso, a guerra causou um "colapso moral"15, mas, de acordo com meus informantes, a chegada de novas igrejas, de- 
pois que a guerra terminou, causou um reavivamento religioso (veja também Cruz e Silva, 2008: 165; Butselaar, 2000). Muitas novas igrejas africanas independentes foram estabelecidas, um processo que já havia começado nos anos 1980, e outras igrejas internacionais também chegaram mais recentemente. Mais curandeiros passaram a trabalhar na cidade. As novas igrejas se beneficiaram da nova liberdade de expressão religiosa e do afrouxamento do controle da Frelimo sobre o espaço da cidade. O crescimento das igrejas também está relacionado com a urbanização rápida durante e depois da guerra civil, passando a atrair os refugiados das áreas rurais para as áreas periurbanas, onde as igrejas africanas independentes, em particular, encontraram terreno fértil.

Muitas dessas novas igrejas tornaram-se particularmente populares entre as muIheres, ou pelo menos tinham um apelo diferente para as mulheres em comparação aos homens (Agadjanian, 1999; Cruz e Silva, 2001b; 2008; Mateus, 2001; Pfeiffer, 2002; Pfeiffer et alii, 2007). Todos esses autores observam um vínculo importante entre a feminização da cidade e a negligência simultânea em relação à realidade socioeconômica por parte do governo, o que poderia explicar o aumento das práticas religiosas em Moçambique. Apontam ainda para a incapacidade de o Estado organizar as condições básicas de subsistência na cidade, o que tornou a vida especialmente difícil para as mulheres, responsáveis pela administração da casa e educação dos filhos. Cruz e Silva (2008: 170) descreve como as igrejas africanas independentes são constituídas "pelos periféricos e marginalizados par excellence". Pfeiffer et alii (2007) argumentam que as mulheres em Chimoio, província de Manica, estão cada vez mais em busca de ajuda espiritual em igrejas africanas independentes, bem como nas igrejas pentecostais, para solucionar problemas de saúde reprodutiva, enquanto os homens permanecem visitando curandeiros tradicionais e envolvendo-se em práticas "ocultas" para gerenciar seus infortúnios relacionados ao emprego. Os programas de ajustamento estrutural de reforma econômica aprofundaram as desigualdades econômicas e exacerbaram as tensões domésticas, afetando homens e mulheres de forma diferente. Isso pode ser observado nos padrões de frequência à igreja.

Entretanto, as mais recentes igrejas pentecostais, principalmente nas áreas urbanas da África Austral, estão atraindo mulheres que não têm uma posição marginalizada em termos socioeconômicos (Frahm-Arp, 2010; Kamp, 2011). Convertidos pentecostais são muitas vezes economicamente bem-sucedidos ou, pelo menos, levam consigo o potencial de mobilidade ascendente. Mesmo quando esses convertidos são malsucedidos economicamente - uma das razões mencionadas pelas mulheres para frequentarem a igreja pentecostal -, sua participação no espaço urbano é diferente dos cidadãos "marginalizados", pois não estão necessariamente entre os "descontentes da modernidade" (modernity's malcontents) (Comaroff \& Comaroff, 
1993). As novas igrejas estão repletas de mulheres médicas, professoras, empresárias e frequentadoras das escolas, universidades e dos cursos. Até agora, pouco se sabe, no entanto, sobre como as igrejas pentecostais estão influenciando a autopercepção dessas mulheres quanto à sua participação na esfera pública.

Defendo que não é a marginalidade das mulheres, mas sua presença cada vez mais central, que está criando novos desafios e tensões que definem suas atividades religiosas. Mulheres, com uma mobilidade socioeconômica em ascensão, estão conquistando espaços supostamente masculinos, e como elas sempre foram relativamente marginalizadas nas áreas urbanas, pelo menos nos espaços mais formais nacionais (Loforte, 2003; Sheldon, 2002; Penvenne, 1997), o espaço urbano não é capaz de servir a essas mulheres com mobilidade ascendente. É significativo que hoje em dia muito mais homens e menos mulheres possam ser encontrados nas igrejas protestantes e católicas mais antigas do que nas igrejas africanas independentes e nas igrejas pentecostais. Muitas das mulheres que conheci nas igrejas pentecostais tinham deixado tanto a Igreja Protestante tradicional ou a Católica, reclamando que os problemas reais da vida não estavam sendo lá atendidos - a exemplo do divórcio, da violência doméstica e do papel dos espíritos ancestrais. Essas mulheres sentiam que, como o governo, os líderes daquelas igrejas não estavam enfrentando os desafios e as possibilidades da sociedade urbana de forma adequada. Este sentimento intensificou-se pelas ligações entre as igrejas e os funcionários do Estado. Nos espaços em que a Missão Suíça inicialmente tinha oferecido uma alternativa, na época colonial, para desenvolver uma nova identidade (urbana) (Cruz e Silva, 2001a; Macamo, 1998; 2005), hoje são as igrejas pentecostais que estão ocupando essa posição, principalmente no que se refere às mulheres em processo de mobilidade ascendente. Esse desenvolvimento não pode ser visto de forma independente do caráter transnacional das igrejas pentecostais.

16. Algumas partes desta seção são versões elaboradas de Kamp (2012b: 67 71; 2013: 353-356).

\section{A mobilidade transnacional do pentecostalismo ${ }^{16}$}

Por conta de conexões transnacionais crescentes, formas religiosas de pertença (religious belonging) adquiriram nova intensidade em diferentes partes do mundo, muitas vezes em concorrência com a cidadania nacional. Pentecostais e muçulmanos têm cada vez mais invadido a esfera pública pela apropriação de novas formas de comunicação, mediante o uso de laços transnacionais e meios de comunicação de massa (Csordas, 2009; Hüwelmeier \& Krause, 2009; Marshall, 2001; Meyer \& Moors, 2006; Meyer, 2009; Salih, 2004). Através de suas ligações transnacionais, grupos religiosos oferecem possibilidades de identificação e lealdade que permitem às pessoas contornarem ou confrontarem o Estado-nação e corroerem seu monopólio de identidades e compromissos (Beyer, 2001; Corten \& Marshall-Fratani, 2001; Rudolph \& Piscatori, 1997). 
Com o foco no pentecostalismo, Corten \& Marshall-Fratani (2001) argumentam que o caráter transnacional da religião contemporânea está tomando um novo significado em comparação às atividades missionárias anteriores, uma vez que o papel do Estado-nação tem diminuído e a representação de uma comunidade global pentecostal permite uma abertura de possibilidades para as pessoas que vai além de seu contexto cultural local, proporcionando-lhes outros modos de identificação e pertença ${ }^{17}$ :

In the developing world, the failed promises of the nation-state concerning modernisation have resulted in the de-legitimisation of their "mega-rhetoric of development" and have opened the field to the work of the imagination of everyday individuals, fuelled by images, ideas and resources from elsewhere, to re-script their lives, both individually and collectively, finding new ways to appropriate and inscribe themselves within global modernity (Corten \& Marshall-Fratani, 2001: 3).

A maior parte dos estudos sobre o pentecostalismo transnacional focaliza as conexões Sul-Norte como a presença de igrejas africanas ou latino-americanas na Europa ou nos Estados Unidos (Adogame, 1998; Adogame \& Weissköppel, 2005; Adogame et alii, 2008; Knibbe \& Meulen, 2009; Levitt, 2007; Mafra, 2002; Haar, 2008; Dijk, 2004; Wilkinson, 2006) ${ }^{18}$. Todos esses autores têm analisado, principalmente, o papel do pentecostalismo em situações de migração, seguindo o campo mais amplo de estudos transnacionais.

Transnacionalismo é uma noção que ganhou muita atenção nos estudos sobre globalização nas ciências sociais (e.g. Appadurai, 1996; Basch et alii, 1994; Hannerz, 1996; Sassen, 2007; Smith \& Guarnizo, 1998; Vertovec, 2007). Os primeiros estudos sobre transnacionalismo mostraram as limitações do foco nacional. Análises acadêmicas costumavam posicionar as pessoas em grupos fixos, como tribos, etnias e Estados-nações, enquanto o aumento das atividades transfronteiriças mostrava o contrário com pessoas desenvolvendo identidades múltiplas e fluidas (Gupta \& Ferguson, 1992). Os migrantes, em particular, têm mostrado que os marcadores e os limites de etnicidade e identidade são negociáveis e dependentes do contexto. $\mathrm{Na}$ antropologia, isso resultou que o conceito de etnia se tornou quase impraticável e os antropólogos da migração começavam a ver o transnacionalismo como principal foco de interesse, o que explica porque o conceito surgiu pela primeira vez neste campo de estudos (Mazzucato, 2004: 131; Vertovec, 2007: 963). Estudos tradicionais de migração centravam o foco nos migrantes que deixavam seus países de origem e adotavam uma nova vida no país de destino. Estudos modernos sobre migração levam em consideração que imigrantes desenvolvem redes que abrangem as sociedades de origem e de destino e, como consequência, o fluxo
17. A Igreja Católica é conhecida como uma organização religiosa transnacional. No entanto, aproximando transnacionalismo como processo de transcendência de espaços nacionais coloca as características transnacionais da Igreja Católica em uma perspectiva diferente. Em Moçambique, a Igreja Católica era parte do projeto do Estado colonial e desde a Independência tem se concentrado na africanização, nacionalizando e "moçambicanizando" a Igreja (MorierGénoud, 1996: $33-$ 34). Nesse sentido, a Missão Suíça em Moçambique tinha características mais transnacionais porque criticou o Estado colonial.

18. Para estudos sobre conexões religiosas Sul-Sul, ver Corten \& MarshallFratani, 2001; Oro et alii, 2009; Rocha \& Vásquez, 2013; Dijk, 2003, 2006. 
de pessoas, ideias e mercadorias entre regiões tem sido sensivelmente estimulado (Basch et alii, 1994).

Do mesmo modo, diversos estudos sobre transnacionalismo religioso têm abordado o papel que a religião desempenha na ligação entre as sociedades de origem e de destino (Vertovec, 2004). A questão central é compreender até que ponto a religião transnacional desempenha um papel na preservação de um sentido de continuidade cultural ou no sentido de incentivar mudanças culturais no contato entre os migrantes e a nova sociedade na qual os mesmos são submetidos a uma agenda pública forte, que geralmente enfatiza a integração. Neste contexto, tem-se argumentado que o pentecostalismo transnacional incentiva a estabilidade em situações de mobilidade e prevê a continuidade cultural, oferecendo aos migrantes um "lar longe de casa" ("home away from home") (Adogame, 1998; 2004; Sanneh, 1993; Haar, 1998; Habermas, 2002).

No caso do pentecostalismo brasileiro em Moçambique, no entanto, não estamos lidando com uma comunidade de migrantes brasileiros. Os convertidos são moçambicanos que continuam vivendo em sua própria sociedade e, simultaneamente, participam de um ambiente no qual se desenvolvem relações entre as sociedades brasileira e moçambicana. Qual é exatamente a relevância da religião transnacional e das questões sobre (des)continuidade e (des)integração cultural em um ambiente como esse?

Vários autores têm apontado para a emergência de espaços transnacionais que não são necessariamente criados pela migração internacional, mas por processos de comunicação e intercâmbio gerados pela expansão do capital, da internet ou de outras formas de comunicação entre Estados-nação específicos (Appadurai, 1996; Clifford, 1992; Hannerz, 1996; Meyer \& Moors, 2006; Smith \& Guarnizo, 1998). Esses estudos analisam como cidadãos podem desenvolver identidades que não são necessariamente nacionais, por exemplo, pelo desenvolvimento de subjetividades e identidades baseadas em ideias, costumes, práticas e emoções que entram em suas vidas através de viajantes, da televisão e da internet. É essa ideia - segundo a qual as pessoas se tornam transnacionais, envolvendo-se em estruturas, culturas e ideologias móveis - que é relevante no caso do transnacionalismo pentecostal em Moçambique. Esse processo assume dimensões especiais no pentecostalismo transnacional brasileiro em Moçambique e demonstra o significado local do transnacionalismo e sua incorporação (Glick Schiller \& Cağlar, 2010), no sentido que a proximidade cultural do convertido com a sociedade local emerge como situação crítica (Dijk, 2006). Ao integrarem como membros a sociedade local, de forma diferente das situações de migração, muitos convertidos moçambicanos lutam para que sua moralidade e espiritualidade pentecostal possam permanecer inalteradas, 
sem a influência das circunstâncias, dos poderes ou das realidades culturais locais. Eles querem tornar-se independentes de ligações culturais e espirituais consideradas estritamente moçambicanas, ou seja, sentir-se com maior mobilidade cultural e socioeconômica.

Deixe-me ilustrar isso com um exemplo muito concreto na vida de Márcia, que é também característica da vida de outras mulheres pentecostais de sua idade ${ }^{19}$. Márcia, com 33 anos, na época da minha pesquisa de campo, tinha um diploma universitário e trabalhava como professora em uma escola secundária. Demonstrava medo em casar-se porque não queria levar a mesma vida que levara sua mãe. Queria compartilhar as responsabilidades domésticas com o seu futuro marido, queria manter sua independência financeira e queria um marido fiel. Achava que isso era praticamente impossível. A violência doméstica que a sua mãe e as suas tias sofreram era uma lembrança constante de "como os homens moçambicanos são"20. Todos os dias, Márcia orava a Deus para pedir-Ihe que encontrasse o marido certo, mas ela também pensava que talvez Deus não quisesse que ela se casasse. Sua pastora brasileira também não era casada.

Essa pastora era a líder da Igreja Batista Brasileira Renovada, frequentada por Márcia durante vários anos. Antes, ela frequentara outras igrejas pentecostais, como a Igreja Universal ${ }^{21}$. Segundo Márcia, a pastora tinha uma personalidade forte, que nenhum homem seria capaz de tolerar. "Deus tinha planos diferentes para ela, do que se casar. Talvez, seja assim comigo também", disse Márcia. Um ano após nossa conversa, ela encontrou seu futuro marido (moçambicano) que havia estudado no exterior, onde tinha aprendido a cuidar de sua própria casa, explicou Márcia. Juntos, decidiram construir uma família cristã. Os pais de Márcia tinham se separado quando ela era ainda criança e, em sua opinião, o envolvimento de sua mãe com os espíritos ancestrais - espíritos demoníacos, segundo os pentecostais - contribuiu certamente para o divórcio. Márcia e seu parceiro queriam começar a vida juntos, livres de ligações com os espíritos ancestrais; não queriam submeter-se aos procedimentos do casamento local, o lobolo 22 , porque espíritos ancestrais estavam envolvidos e ficariam dependentes dos laços de parentesco. No entanto, essa decisão criou tensões com parentes de ambos os lados. No início, os pais, tios e tias de Márcia não aceitavam sua escolha e não queriam participar no casamento. Mesmo que desejassem simplesmente conduzir suas próprias vidas, o casal também almejava manter um bom relacionamento com seus respectivos parentes. Após várias negociações, decidiram organizar um ritual de lobolo-cristão, sem invocar os antepassados, e convidar um pastor para abençoar a relação. Assim, criaram uma cerimônia de casamento que outros casais pentecostais passaram a adotar (Kamp \& Dijk, 2010: 130-133).
19. Este não é o seu nome verdadeiro, isso para preservar sua privacidade.

20. Encontreime várias vezes com Márcia. As citações são de uma entrevista e uma conversa que ocorreram em 7 de abril e 21 de abril de 2006, respetivamente.

21. Muitas mulheres circulavam entre as igrejas pentecostais brasileiras, mudando por exemplo, da Deus é Amor para a Igreja Universal e mais tarde para a Igreja Mundial.

22. Lobolo é frequentemente traduzido em inglês como brideprice, mas é uma troca entre as famílias da noiva e do noivo que entram em um relacionamento, incluindo várias cerimônias (Arnfred, 2011: 62-103). 
23. Havia também pastores moçambicanos e pastores de outros países africanos lusófonos, como Angola. No entanto, os brasileiros estavam na liderança das igrejas brasileiras, e a maior parte dos moçambicanos era apenas pastores assistentes ou obreiros. Os pastores moçambicanos têm até mesmo adotado o português do Brasil. Mas essa situação parece estar mudando, entre outras razões por conta da pressão do governo moçambicano, que obriga igrejas estrangeiras a empregarem pastores locais.

24. Em outros trabalhos, descrevi como pastores brasileiros se referem a um passado espiritual compartilhado entre brasileiros e africanos, em relação ao comércio transatlântico de escravos e o surgimento das religiões afrobrasileiras (Kamp, 2012b; 2013).
Ao envolver-se no pentecostalismo transnacional brasileiro, Márcia poderia explorar novas ideias e práticas de casamento e também cogitar a possibilidade em permanecer solteira, poderia antecipar uma trajetória de vida diferente, em comparação à sua mãe, e afastar-se das "forças do mal". Ainda assim, em tais casos, os convertidos tinham medo de que seus parentes pudessem ter envolvido os espíritos familiares, propiciando um ambiente de desconfiança e ansiedade.

Como estrangeiros, os pastores brasileiros ${ }^{23}$ confrontavam os moçambicanos com uma variedade de comportamentos e aspetos de sua cultura e modo de vida. Ao questionarem os poderes dos curandeiros locais, os pastores arremedavam o comportamento de curandeiros em transe. Levavam objetos empregados pelos curandeiros para dentro da igreja e mostravam que podiam tocá-los, sem quaisquer consequências negativas. No contexto moçambicano, isso é considerado ofensivo e perigoso, mas os pastores mostravam que não se deve ter medo quando se está sob a proteção do poder ilimitado do Espírito Santo ${ }^{24}$.

Outro exemplo é a terapia do amor, organizada pela Igreja Universal (Kamp, 2013). Durante uma sessão da terapia, o pastor imitou o comportamento de casais moçambicanos que, de acordo com os brasileiros, são tímidos, não têm a coragem de olhar um nos olhos do outro ou tocar seu parceiro em espaços públicos. Em seguida, o pastor, de mãos dadas com a sua esposa, abraçou-a e deu-lhe um beijo para mostrar o que é o verdadeiro amor, mas também para demonstrar as deficiências dos costumes locais. Ao fazer tudo isso abertamente, em uma sociedade onde geralmente parceiros não se abraçam em público, os pastores queriam abrir e quebrar a força dos valores culturais locais, como forma de provocar sua transformação. Impelem, assim, os convertidos a cruzarem fronteiras culturais e espirituais.

Moçambicanos pentecostais não viajam literalmente na travessia de fronteiras. Pastores brasileiros têm feito isso e é a sua trajetória que cria um espaço de mobilidade sociocultural. Mariz (2009) descreve o deslocamento de pastores brasileiros, dentro e fora do Brasil, que deixam suas casas e famílias para pregar o evangelho. Isso é valorizado como importante estratégia de desenvolvimento espiritual, porque, deixando a família, é possível dedicar-se inteiramente ao projeto missionário. A viagem geográfica facilita uma ruptura radical com a vida anterior e permite a formação de uma nova pessoa. Durante os cultos nas igrejas em Moçambique, pastores brasileiros frequentemente utilizavam as suas jornadas pessoais como um exemplo do que a fé significa e do que ela pode proporcionar. Para transformar é preciso viajar e transcender o familiar, incluindo sua família e sua cultura, assim como sofrer dificuldades para criar novas possibilidades. Ao participar do pentecostalismo brasileiro, a pessoa embarca em uma nova jornada. Crentes moçambicanos deixam elementos 
da cultura local para trás, começando a experimentar a vida de maneira diferente e a enxergar as coisas sob uma nova luz. Apesar de seus corpos permanecerem no mesmo local fisicamente, o deslocamento subjetivo dos convertidos e seus posicionamentos transnacionais, pela participação no pentecostalismo brasileiro, produzem efeito semelhante ao de embarcar em uma verdadeira viagem em relação a percepções sociais e culturais, valores e práticas.

Mesmo que o rompimento com estruturas e práticas socioculturais consista em um aspeto intrínseco do pentecostalismo na África (Meyer, 1998), este está sendo reforçado pela dimensão transnacional Sul-Sul. Em continuidade com a tradição de práticas de cura e com os trabalhos de missão no sudeste da África, que envolviam práticas espirituais e rituais para transcender situações consideradas limitantes e para conhecer novas realidades e possibilidades, os pastores brasileiros são percebidos como "curandeiros" bem poderosos. A mobilidade que o pentecostalismo brasileiro particularmente efetua faz com que uma pessoa se torne "estrangeira" no ambiente local, e não uma pessoa "integrada" em uma realidade estranha (Werbner, 1989), como se argumentou em relação ao pentecostalismo africano na Europa (Dijk 1997).

Em vez disso, no movimento transnacional Sul-Sul do pentecostalismo brasileiro, o enfoque em uma ruptura com os costumes culturais mostra a religião como produtora de um lugar "estranho" (Kamp \& Dijk, 2010). Ao atravessar fronteiras culturais e espirituais, portanto, a experiência não é experimentada como desconcertante ou desenraizante, e se tais sentimentos surgem, a igreja não fornece um "lar", lembrando o "home away from home" (Adogame, 1998). O espaço transnacional pentecostal diz respeito à criação de uma transformação, transcendendo abertamente as fronteiras nacionais, culturais e espirituais; cortando, por exemplo, relações de dependência com parentes; incorporando novos modos de amar, abraçando e beijando o cônjuge em público.

Uma atmosfera de contestação e de luta deve ser criada para garantir avanços e transformação. Uma nova vida só pode se desenvolver quando hábitos antigos forem contestados, como o de questionar abertamente o poder de curandeiros e parentes (ancestrais). A partir de suas experiências transnacionais, os pastores desenvolvem uma posição superior nessa luta e incentivam convertidos a fazerem o mesmo. Pastores brasileiros confrontam seu público com os poderes espirituais que estão envolvidos em seu dia a dia, estimulando reflexões sobre a sociedade local com o objetivo de criar uma posição distante em relação a circunstâncias locais. Como resultado, ideologias, práticas e experiências específicas se desenvolvem, tais como aquelas retratadas em relação ao lobolo, os papéis de gênero, o parentesco e a família. 


\section{Conclusão}

O envolvimento religioso produz formas de mobilidade. Historicamente, as competências dos diferentes tipos de curandeiros no sudeste africano têm sido atribuídas à sua capacidade de atravessar fronteiras linguísticas, científicas, espirituais, nacionais e culturais. Dessa forma, curandeiros, pastores, profetas e missionários também criaram as condições para que outros pudessem ter mais mobilidade em termos culturais, espirituais e socioeconômicos. Durante o período colonial em Moçambique, por exemplo, as missões protestantes e católicas ofereciam novas oportunidades, como a educação. Hoje, o pentecostalismo transnacional brasileiro está gerando transformação para mulheres urbanas relativamente bem-sucedidas socioeconomicamente.

Essa análise defende que o pentecostalismo transnacional - e especialmente suas ligações Brasil-Moçambique - são cruciais para a compreensão da participação pentecostal de mulheres com uma mobilidade ascendente em Maputo. O envolvimento pentecostal estimula as mulheres a desenvolverem uma posição crítica em relação a culturas locais, fato reforçado pelas dimensões transnacionais das igrejas pentecostais e por seus pastores. Moçambicanos que participam nas igrejas pentecostais brasileiras tornam-se transnacionais, pois embarcam em uma viagem em relação a percepções, valores e práticas sociais e culturais. Eles atravessam subjetivamente as fronteiras nacionais, na medida em que criticam e se distanciam de certos costumes e de certas crenças locais. Assim, o pentecostalismo brasileiro em Moçambique contribui para uma consciência cultural crítica e para uma desestabilização de continuidade cultural, tornando as pessoas "estrangeiras" dentro de sua própria sociedade, ao invés de serem "integradas". Nesse sentido, convertidos pentecostais em Moçambique não necessariamente respondem a situações de mobilidade, como nos processos de globalização e migração tradicionais, ao contrário, criam mobilidades socioculturais através do poder do Espírito Santo para conquistar novos modos de ser e fazer.

O espaço transnacional pentecostal Sul-Sul tornou-se especialmente relevante para as mulheres urbanas com mobilidade socioeconômica ascendente que estão buscando novas formas para dirigir e controlar as suas novas posições em um ambiente urbano mutável e incerto, mas desafiador. Incertezas sobre as novas formas de viver demandam uma reflexão crítica cultural, especialmente no que diz respeito às relações com parentes e parceiros. A abertura explícita dos pastores brasileiros em relação às questões de amor, casamento e relações de parentesco para além de sua força espiritual e cross-cultural, permite-lhes atravessar fronteiras culturais sensíveis, torna-os curandeiros e conselheiros atraentes quando se trata de reformar questões de gênero, parentesco e casamento. Ao navegarem no 
pentecostalismo transnacional, essas mulheres estão explorando novas possibilidades e antecipando uma trajetória de vida para encontrar e criar novas formas de conhecimento cultural, espiritual e de vida. Ao mesmo tempo, o confronto explícito no pentecostalismo brasileiro em relação aos conhecimentos e às práticas locais não só torna possível atravessar limites, mas ainda cria novas fronteiras.

É importante perceber que enquanto os convertidos desenvolvem novas posições socioculturais, também novas incertezas culturais e espirituais manifestam-se. Por exemplo: nos casos em que os convertidos expressavam receio de seus parentes envolverem os espíritos familiares em seu lobolo pentecostal. Assim, a mobilidade do pentecostalismo brasileiro em Moçambique oferece a possibilidade de transcender fronteiras socioculturais e espirituais, criando novos modos de conhecimento e de práticas culturais e, simultaneamente, esta mobilidade levanta novos limites como resultado das contestações entre as diferentes formas de conhecimento.

Abstract: Based on ethnographic research carried out in Maputo, the capital of Mozambique, this contribution argues that transnational Pentecostalism and especially its South-South or Brazil-Mozambique links are crucial to understanding upwardly mobile women's Pentecostal involvement. In line with a history of religion and healing in Southeast Africa that have shaped conditions to become more mobile culturally, spiritually and socio-economically, transnational Pentecostalism stimulates upwardly mobile women to develop their critical position towards local cultures. Mozambican women who participate in the Brazilian Pentecostal churches become transnational because they cross national boundaries subjectively by criticizing and distancing themselves from local forms of cultural and spiritual knowledge. Brazilian Pentecostalism in Mozambique contributes to a critical cultural awareness and a destabilization of cultural traditions by making people an 'outsider' in their society. In this sense, Pentecostal women do not necessarily respond to situations of mobility, such as processes of globalization, but instead create mobility. Their participation in transnational Pentecostalism generates the power of the Holy Spirit to conquer new modes of being and doing, particularly in the fields of gender, kinship and marriage.

Keywords: Brazilian pentecostalism, South-South transnationalism, cultural and spiritual mobility, Mozambique.

\section{Referências}

ADOGAME, Afe. Engaging the rhetoric of spiritual warfare: the public face of aladura in diaspora. Journal of Religion in Africa, v. 34, n. 4, p. 493-522, 2004.

- A home away from home: the proliferation of celestial church of Christ in diaspora Europe. Exchange - Journal of Missiological and Ecumenical Research, v. 27, n. 2, p. 141-160, 1998. 
ADOGAME, Afe; GERLOFF, Roswith; HOCK, Klaus (Eds.). Christianity in Africa and the african diaspora: the appropriation of a scattered heritage. London: Continuum Books, 2008.

ADOGAME, Afe; WEISSKÖPPEL, Cordula (Eds.). Religion in the context of african migration. Bayreuth: Breitinger, 2005.

AGADJANIAN, Victor. As igrejas Zione no espaço sociocultural de Moçambique urbano (anos 1980 e 1990). Lusotopie, v. 6, n. 1-2, p. 415-423, 1999.

ANDERSON, Allan. An introduction to pentecostalism: global charismatic christianity. Cambridge (UK): Cambridge University Press, 2004.

ANDRADE, Ximena; LOFORTE, Ana Maria; OSÓRIO, Conceição; RIBEIRO, Lúcia; TEMBA Eulália. Famílias em contexto de mudança em Moçambique. 2. ed. Maputo: Women and Law in Southern Africa Moçambique, 2001.

APPADURAI, Arjun. Modernity at large. Cultural dimensions of globalization. Minneapolis (MI): University of Minnesota Press, 1996.

ARNFRED, Signe. Sexuality and gender politics in Mozambique. Rethinking gender in Africa. Oxford: James Currey in cooperation with the Nordic African Institute, 2011.

ASAMOAH-GYADU, J. Kwabena. Contemporary pentecostal christianity; interpretations from an african context. Eugene (OR): WIPF \& Stock, Regnum Studies in Global Christianity, 2013.

BASCH, Linda; GLICK SCHILLER, Nina; SZANTON BLANC, Cristina. Nations unbound. Transnational projects, postcolonial predicaments, and deterritorialized nation-states. Langhorne (PA): Gordon and Breach, 1994.

BAGNOL, Brigitte. Gender, self, multiple identities, violence and magical interpretations in lovolo practices in Southern Mozambique. (Tese) - Doutorado, Universidade de Cape Town, 2006.

BEYER, Peter. Religion in the process of globalization. Wurzburg: Ergon Verlag, 2001.

BUTSELAAR, Jan van. The role of religion in Africa today. A report from Mozambique. Neue Zeitschrift für Missionswissenschaft, v. 56, n. 2, p. 133-140, 2000. 
- Africanos, missionarios e colonistas. As origens da Igreja Presbiteriana de Moçambique (Missão Suiça), 1880-1896. Lausanne: Département Missionaire des Églises Protestantes de la Suisse Romande, 1987.

CARVALHO, Francisco Coelho de. Representações sociais do HIV/Sida numa comunidade religiosa: o caso das Testemunhas de Jeová da Congregação de Sommerschield (cidade de Maputo). (Monografia) - Licenciatura, Departamento de Sociologia, Faculdade de Letras e Ciências Sociais, Universidade Eduardo Mondlane, Maputo, 2005.

CASIMIRO, Isabel. "Paz na Terra, guerra em casa": feminismo e organizações de mulheres em Moçambique. Maputo: Promédia, 2004.

- Transformações nas relações homem/mulher em Moçambique, 1960-1974. (Monografia) - Licenciatura, Universidade Eduardo Mondlane, Maputo, 1986.

CHESNUT, Andrew. Born again in Brazil: the pentecostal boom and the pathogens of poverty. New Brunswick (NJ): Rutgers University Press, 1997.

CLIFFORD, James. Traveling cultures. In: GROSSBERG, L.; NELSON, C.; TREICHLER, P. A. (Eds.). Cultural studies, p. 96-116. New York: Routledge, 1992.

COLEMAN, Simon. The globalisation of charismatic christianity: spreading the gospel of prosperity. Cambridge (UK): Cambridge University Press, 2000.

COMAROFF, Jean; COMAROFF, John. Of revelation and revolution: christianity, colonialism, and consciousness in South Africa. v. 2, The dialectics of modernity on a south african frontier. Chicago (MA): University of Chicago Press, 1997.

- Modernity and its malcontents: ritual and power in Africa. Chicago (MA): University of Chicago Press, 1993.

CORTEN, André; MARSHALL-FRATANI, Ruth (Eds.). Between Babel and pentecost. Transnational pentecostalism in Africa and Latin America. London: Hurst \& Company, 2001.

CRUZ E SILVA, Teresa. Evangelicals and democracy in Mozambique. In: RANGER, T. (Ed.). Evangelical christianity and democracy in Africa, p. 161-189. Oxford: Oxford University Press, 2008.

- Protestant churches and the formation of political consciousness in Southern Mozambique (1930-1974). Basel: Schlettwein Publishing, 2001a. 
- Entre a exclusão social e o exercício da cidadania: igrejas "Zione" do bairro Luís Cabral, na cidade de Maputo. Estudos Moçambicanos, n. 19, p. 61-88, 2001 b.

CSORDAS, Thomas J. (Ed.). Transnational transcendence: essays on religion and globalization. Davis (CA): University of California Press, 2009.

DIJK, Rijk van. Transnational images of pentecostal healing: comparative examples from Malawi and Botswana. In: LUEDKE, T. J.; WEST, H. G. (Eds.). Borders and healers: brokering therapeutic resources in Southeast Africa, p. 101-124. Bloomington (IN): Indiana University Press, 2006.

- Negotiating marriage: questions of morality and legitimacy in the ghanaian pentecostal diaspora. Journal of Religion in Africa, v. 34, n. 4, p. 438-467, 2004.

- Localisation, ghanaian pentecostalism and the stranger's beauty in Botswana. Africa, v. 73, n. 4, p. 560-583, 2003.

- From camp to encompassment: discourses of transsubjectivity in the ghanaian pentecostal diaspora. Journal of Religion in Africa, v. 27, n. 2, p. 135-159, 1997.

FEIERMAN, Steven. Afterword: ethnographic regions - healing, power, and history. In: LUEDKE, T. J.; WEST, H. G. (Eds.). Borders and healers: brokering therapeutic resources in Southeast Africa, p. 185-194. Bloomington (IN): Indiana University Press, 2006.

FRAHM-ARP, Maria. Professional women in south african pentecostal charismatic churches. Leiden: Brill, 2010.

FRESTON, Paul. The Universal Church of the Kingdom of God: a brazilian church finds success in Southern Africa. Journal of Religion in Africa, v. 35, n. 1, p. 33-65, 2005.

- Evangelicals and politics in Asia, Africa and Latin America. Cambridge: Cambridge University Press, 2001.

GENNEP, Anton van. The rites of passage. London: Routledge and Kegan Paul, 1980 [1976].

GIFFORD, Paul. Ghana's new christianity: pentecostalism in a globalising african economy. London: Hurst \& Company, 2004.

GLICK SCHILLER, Nina; ÇAĞLAR, Ayse (Eds.). Locating migration: rescaling cities and migrants. Ithaca (NY): Cornell University Press, 2010. 
GRANJO, Paulo. The homecomer: postwar cleansing rituals in Mozambique. Armed Forces \& Society, v. 33, n. 3, p. 382-395, 2007.

GUPTA, Akhil; FERGUSON; James. Beyond "culture": space, identity, and the politics of difference. Cultural Anthropology, v. 7, p. 6-23, 1992.

HAAR, Gerrie. African christians in Europe. In: KUNTER, K.; SCHJ ØRRING, J. H. (Eds.). Changing relations between churches in Europe and Africa: the internationalization of christianity and politics in the 20th century, p. 241-251. Wiesbaden: Harrassowitz, 2008.

- The african diaspora in the Netherlands. In: CLARKE, P. B. (Ed.). New trends and developments in african religions, p. 245-262. Westport (CT): Greenwood Press, 1998.

HABERMAS, Jürge. Religion and rationality: essay on reason, god, and modernity. Cambridge: Massachusetts Institute of Technology Press, 2002.

HANNERZ, UIf. Transnational connections. culture, people, places. London: Routledge, 1996.

HARRIES, Patrick. Junod e as sociedades africanas. impacto dos missionários suíços na África Austral. Maputo: Paulinas, 2007.

HELGESSON, Alf. Church, State, and people in Mozambique: an historical study with special emphasis on methodist developments in the Inhambane Region. Uppsala: Swedish Institute of Missionary Research, 1994.

HÜWELMEIER, Gertrud; KRAUSE, Kristine (Eds.). Traveling spirits: migrants, markets and mobilities. London: Routledge, 2009.

KAMP, Linda van de. South-South transnational spaces of conquest: afro-brazilian pentecostalism, "feitiçaria" and the reproductive domain in urban Mozambique. Exchange: A Journal of Missiological and Ecumenical Research, v. 42, n. 4, , p. 343-365, 2013.

. Afro-Brazilian pentecostal re-formations of relationships across two generations of mozambican women. Journal of Religion in Africa, v. 42, n. 4, p. 433-452, 2012a.

—. Pentecostalismo brasileiro, "macumba" e mulheres urbanas em Moçambique. In: ORO, A. P.; STEIL, C. ; RICKLI, J. (Orgs.). Transnacionalização religiosa: fluxos e redes, p. 59-76. "Antropologia Hoje". São Paulo: Editora Terceiro Nome, 2012b. 
- Violent conversion: brazilian pentecostalism and the urban pioneering of women in Mozambique. (Tese) - Doutorado, Universidade Livre de Amsterdã, 2011.

KAMP, Linda van de; DIJK, Rijk van. Pentecostals moving South-South: brazilian and ghanaian transnationalism in Southern Africa. In: ADOGAME, A.; SPICKARD, J. (Eds.). Religion crossing boundaries: transnational dynamics in Africa and the new african diasporic religions, p.123-142. Leiden: Brill, 2010.

KNIBBE, Kim; MEULEN, Marten van der (Eds.). The role of spatial practices and locality in the constituting of the christian african diaspora. African Diaspora: A Journal of Transnational Africa in a Global World, v. 2, n. 2, p. 124-244, 2009.

KOEVERING, Helen van. Recent developments in mozambican christianity. In: GIFFORD, P. (Ed.). New dimensions in african christianity, p. 103-134. Nairobi: All Africa Conference of Churches, "African Challenge Series", n. 3, 1992.

LEVITT, Peggy. God needs no passport: immigrants and the changing american religious landscape. New York: The New Press, 2007.

LOFORTE, Ana Maria. Género e poder entre os Tsonga de Moçambique. Lisboa: Ela por Ela, 2003.

LUEDKE, Tracy; WEST, Harry G. (Eds.). Borders and healers: brokering therapeutic resources in Southeast Africa. Bloomington (IN): Indiana University Press, 2006.

LUEDKE, Tracy. Spirit and matter: the materiality of mozambican prophet healing. Journal of Southern African Studies, v. 33, n. 4, p. 715-731, 2007.

LUNDIN, Iraê Baptista. Negotiating transformation: urban livelihoods in Maputo adapting to thirty years of political and economic changes. Göteborg: Department of Human and Economic Geography, School of Business, Economics and Law, Göteborg University, 2007.

MACAMO, Elísio S. Denying modernity: the regulation of native labour in colonial Mozambique and its postcolonial aftermath. In: MACAMO, E. S. (Ed.). Negotiating modernity: Africa's ambivalent experience, p. 67-97. London; Dakar; Pretoria: Zed Books; Codesria Books; University of South Africa Press, 2005.

. A influência da religião na formação de identidades sociais no sul de Moçambique. In: SERRA, C. (Org.). Identidade, moçambicanidade, moçambicanizão, p. 35-69. Maputo: Livraria Universitária, Universidade Eduardo Mondlane, 1998. 
MAFRA, Clara. Na posse da palavra: religião, conversão e liberdade pessoal em dois contextos nacionais. Lisboa: Imprensa de Ciências Sociais; Instituto de Ciências Sociais, Universidade de Lisboa, 2002.

MARIZ, Cecilia Loreto. Igrejas pentecostais brasileiras no exterior. Análise Social, v. XLIV, n. 1, p. 161-187, 2009.

MANUEL, Sandra. Maputo has no marriage material: sexual relationships in the politics of social affirmation and emotional stability in a cosmopolitan african city. (Tese) - Douorado, School of Oriental and African Studies, London, 2011.

MARSHALL, Ruth. The global and local in nigerian pentecostalism. In: CORTEN, André; MARSHALL-FRATANI, Ruth (Eds.). Between Babel and pentecost. Transnational pentecostalism in Africa and Latin America, p. 80-105. London: Hurst \& Company, 2001.

MATEUS, Valentina. Crentes e problemas sociais nas igrejas zione da cidade da Beira. Estudos Moçambicanos, n. 18, p. 161-179, 2001.

MAZZUCATO, Valentina. Transcending the nation. Explorations of trans nationalism as a concept and phenomenon. In: KALB, D.; PANSTERS, W.; SIEBERS, H. (Eds.). Globalization \& development. Themes and concepts in current research, p. 131-162. Dordrecht: Kluwer Academic Publishers, 2004.

MENESES, Maria Paula G. O "indígena" africano e o colono "europeu": a construção da diferença por processos legais. In: RODRÍGUEZ MAESO, S. (Org.). Identidades, cidadanias e estado: estratégias políticas e governamentalidade, p. 68-93. Coimbra: E-cadernos Centro de Estudos Sociais n. 4, 2010.

MEYER, Birgit. Pentecostalism and globalization. In: ANDERSON, A.; BERGUNDER, M. ; DROOGERS, A.; VAN DER LAAN, C. (Eds.). Studying global pentecostalism: theories and methods, p. 113-129. Berkeley: University of California Press, 2010.

_. "Make a complete break with the past": memory and postcolonial modernity in ghanaian pentecostal discourse. Journal of Religion in Africa, v. 28, n. 3, p. 316-349, 1998.

MEYER, Birgit (Ed.). Aesthetic formations. Media, religion and the senses in the making of communities. New York: Palgrave, 2009.

MEYER, Birgit; MOORS, Annelies (Eds.). Religion, media and the public sphere. Bloomington (IN): Indiana University Press, 2006. 
MORIER-GÉNOUD, Eric. Of God and Caesar. The relation between christian churches and the State in post-colonial Mozambique, 1974-1981. Le Fait Missionaire, n. 3, p. 1-79, 1996.

ORO, Ari Pedro; CORTEN, André; DOZON, Jean-Pierre. Igreja Universal do Reino de Deus: os novos conquistadores da fé. São Paulo: Paulinas, 2003.

ORO, Ari; ALVES Daniel; MEIRELLES, Mauro; BEM, Daniel Francisco de. Transnacionalização religiosa. Debates do NER, v. 10, n. 16, 2009.

PFEIFFER, James. African independent churches in Mozambique: healing the afflictions of inequality. Medical Anthropology Quarterly, v. 16, n. 2, p.176-199, 2002.

PFEIFFER, James; GIMBEL-SHERR, Kenneth; ORVALHO, Joaquim Augusto. The holy spirit in the household: pentecostalism, gender, and neoliberalism in Mozambique. American Anthropologist, v. 109, n. 4, p. 688-700, 2007.

PENVENNE, Jeanne Marie. Seeking the factory for women. Mozambican urbanization in the late colonial era. Journal of Urban History, v. 23, n. 3, p. 342-379, 1997.

PINSKY, Barry. The urban problematic in Mozambique: initial post-independence responses, 1975-80. Toronto: University of Toronto, Centre of Urban and Community Studies, 1982.

REKDAL, Ole Bjørn. Cross-cultural healing in east african ethnography. Medical Anthropology Quarterly, p. 458-482, v. 13, n. 4, 1999.

ROCHA, Cristina; VÁSQUEZ Manuel A. (Orgs.). The diaspora of brazilian religions. "International Studies in Religion and Society", v. 16. Leiden: Brill, 2013.

ROSSOUW, G.J.; MACAMO JR. Eugenio. Church-State relationship in Mozambique. Journal of Church and State, v. 35, n. 3, p. 537-546, 1993.

RUDOLPH, Susanne H.; PISCATORI, James (Eds.). Transnational religion and fading States. Boulder: Westview Press, 1997.

SALIH, Ruba. The backward and the new: national, transnational and post-national islam in Europe. Journal of Ethnic and Migration Studies, v. 30, n. 5, p. 995-1011, 2004.

SANNEH, Lamin. Encountering the West. Christianity and the global cultural process: the african dimension. New York: Orbis Books, 1993. 
SASSEN, Saskia. A sociology of globalization. New York: W.W. Norton, 2007.

SCHOFFELEERS, Jan-Mathijs (Ed.). Guardian of the land: essays on Central African territorial cults. Gwelo: Mambo Press, 1979.

SEIBERT, Gerhard. "But the Manifestation of the spirit is given to every man to profit withal". Zion churches in Mozambique since the early 20th Century. Le Fait Missionnaire, n. 17, p. 125-150, 2005.

SHELDON, Kathleen E. Pounders of grain: a history of women, work, and politics in Mozambique. Portsmouth (NH): Heinemann, 2002.

SMITH, Michael Peter; GUARNIZO, Luis Eduardo (Eds.). Transnationalism from below. New Brunswick: Transaction Publishers, 1998.

TURNER, Victor. The forest of symbols: aspects of Ndembu ritual. Ithaca (NY): Cornell University Press, 1967.

UPTON, George R. The miracle of Mozambique. The overseas missions department of the pentecostal assemblies of Canada. Clearbrook (BC): A. Olfert \& Sons Ltd, 1980 .

VERTOVEC, Steven. Introduction: new directions in the anthropology of migration and multiculturalism. Ethnic and Racial Studies, v. 30, n. 6, p. 961-978, 2007.

- Religion and diaspora. In: ANTES, P.; GEERTZ, A. W.; WARNE, R. R. (Eds.). New approaches to the study of religion, p. 275-303. Berlin: Walter de Gruyte, 2004.

VINES, Alex; WILSON, Ken. Churches and the peace process in Mozambique. In: GIFFORD, P. (Ed.). The christian churches and the democratization of Africa, p. 130-147. Leiden: Brill, 1995.

WERBNER, Richard. Ritual passage, sacred journey: the process and organization of religious movement. Washington (DC); Manchester: Smithsonian Institution Press; Manchester University Press, 1989.

WERBNER, Richard (Ed.). Regional cults. New York: Academic Press, 1977.

WEST, Harry G. Kupilikula. Governance and the invisible realm in Mozambique. Chicago: Chicago University Press, 2005. 
WHYTE, Susan Reynolds. The power of medicines in East Africa. In: VAN DER GEEST, S.; REYNOLDS WHYTE, S. (Eds.). The context of medicines in developing countries: studies in pharmaceutical anthropology, p. 217-233. Dordrecht: Kluwer Academic Publishers, 1988.

WILKINSON, Michael. The spirit said go: pentecostal immigrants in Canada. New York: Peter Lang, 2006.

DOI: $10.1590 / S 0102-699220150002000007$ 